\title{
LA MÚSICA DE BAUDELAIRE
}

\author{
Sergio Cueto \\ Universidad Nacional de Rosario \\ sergiojcueto@hotmail.com
}

Resumen: A partir de una lectura del poema "La música", y a través de referencias a otros lugares de la obra baudelairiana, se intenta situar el pensamiento musical de Baudelaire, es decir, aquél que resulta disonante respecto de su reflexión crítica (particularmente respecto de la música wagneriana) y que, entendemos, se encabalga entre el infinito de la Sehnsucht romántica y la crispación del Spleen moderno.

Palabras clave: Baudelaire, Música, Mar, Infinito, Spleen.

\begin{abstract}
From a reading of the poem "La musique", and through references to other places in the Baudelairean work, we try to situate the musical thought of Baudelaire, that is, one that is dissonant with respect to his critical consideration (particularly regarding the Wagnerian music) and that is embedded between the infinity of the romantic Sehnsucht and the tension of the modern Spleen.
\end{abstract}

Keywords: Baudelaire, Music, Sea, Infinit, Spleen. 
Aunque referencia frecuente, la música es sin embargo motivo de un solo poema en toda la obra de Baudelaire. El poema, un soneto que se diría claudicante, en el sentido etimológico de la palabra, puesto que, construido con alejandrinos y pentasílabos alternados, parece renguear, dice menos lo que la música es que la experiencia de la escucha de una cierta música. ¿Qué música es ésta? ¿Cuál es la música de Baudelaire? Leamos el poema. Es una traducción circunstancial, hecha a los efectos de la comprensión y el análisis.

¡La música a menudo me cautiva como el mar! Hacia mi pálida estrella, Bajo un techo de bruma o en el vasto éter, Me hago a la vela;

Con el pecho adelante y los pulmones hinchados Igual que la tela, Trepo a la espalda de las olas amontonadas Que la noche me vela;

Siento vibrar en mí las pasiones todas

De un barco que sufre; El apacible viento y la tempestad convulsa

Sobre el abismo inmenso Me acunan. Otras veces, calma chicha, gran espejo De mi melancolía.

La música es como el mar. El mar cautiva, es decir, no sólo fascina, atrae y retiene el ánimo sino que literalmente captura, atrapa, prends, dice Baudelaire, rapta y lleva consigo, arrebata hasta el éxtasis, enajena y extravía al que escucha. Naufragar es 
dulce en ese mar. La alegoría, sin embargo, es posible por un elemento inesperado y aparentemente fútil: el espacio. Por un lado, en efecto, Baudelaire recuerda una y otra vez que el mar expresa la idea de espacio, que la fascinación que despierta el mar obedece a que el hombre contempla en él las ideas de inmensidad y movimiento. Infinito en diminutivo, el mar sugiere la idea del infinito. $Y$ ya en esta idea, ya en la promesa del infinito aguarda el movimiento. Porque el infinito no es tanto expresión de una idea como el esfuerzo y la dirección hacia ella. Representa un intento posible hacia una concepción imposible, según la fórmula que Baudelaire pudo encontrar en Poe. El infinito es a la vez camino y meta. Por eso apenas por encima del horizonte, como señalando la lejanía misma del mar, pone Baudelaire la pálida estrella del Ideal. El movimiento infinito hacia el infinito en el infinito es lo que se llama el viaje. El problema con el viaje es que tarde o temprano se llega a alguna parte, y ese puerto sólo sirve para que el navío encalle. En tal sentido, la música es una redención del viaje. Si escuchar música es como navegar o nadar en un mar sonoro es porque la música descubre otro movimiento en el movimiento, libera al movimiento de su origen y su fin y así quizá de su sentido. Georges Poulet ha observado muy bien que viajar, nadar, volar, es en Baudelaire un movimiento continuo que abraza la duración, como una vibración que se expande. Habría, dice, en Baudelaire, una cierta espacialización del tiempo. La extensión temporal es un instante que se infla. El presente no fluye, se dilata; no es un punto ni una sucesión sino como una ola en una marea, tiempo que se abre, que envuelve y arrastra, igual que el tiempo de la escucha, el tiempo de la música, tal como 
lo descubren, cada uno por su lado, Jeanne Hersch y Jean-Luc Nancy. El viaje, el movimiento en el mar de la música es lo que se llama la emoción. Musicalmente, la emoción encuentra expresión en la melodía. Mecido por el oleaje de una melodía infinita con la que se confunde como una ola se confunde o no alcanza a distinguirse del oleaje, el oyente se abandona voluntariamente al naufragio de la voluntad, ya casi se ha olvidado en el anhelo del olvido. Es, se habrá advertido, la descripción heideggeriana de la música de Wagner: la barbarización del sentimiento sin forma ni fondo y la redención de la vida por el sueño y el olvido. Sin embargo, ¿es ésta la música de Baudelaire? ¿Siquiera es ésta la música de "La música”?

La música es como el mar. El mar es una imagen de la música. El poema le da una imagen a lo que es sin imagen, a lo que no es imagen de nada, salvo, quizá, del infinito, que es sin imagen. Por eso el mar no es del todo una imagen, es una imagen que no da a imaginar nada o que da a imaginar precisamente nada, imagen sin imagen, de nuevo como el infinito. La imagen del mar expresa en Baudelaire la idea de infinito, es decir, de espacio. "La inmensidad sin otro decorado que ella misma", dice Baudelaire: esto es el mar. Por eso su imagen es apropiada para la música. La música, en efecto, da la idea de espacio, al menos así se dice en Mi corazón al desnudo. Pero no es que al escuchar música uno piense en el espacio sino que uno siente el espacio en la música. La música está dentro tuyo como aquello en lo que estás, la llevas como aquello que te lleva cuando la escuchas. Ella es como la intimidad del afuera. Pero porque es espacio, dice Baudelaire, 
la música es asimismo número, ya que el número es una traducción del espacio. El número traduce el espacio introduciendo la discontinuidad en el continuo, la multiplicidad en la unidad. Por el número, el mar ya no es un solo indefinido oleaje sino un conjunto virtualmente infinito pero discreto de olas amontonadas. El número dice que las olas son muchas, que el mar es multitudinario. El mar deviene numeroso por el número, pero numeroso quiere decir precisamente innumerable. El número no cuenta, dice más bien cómo es incontable lo incontable. El infinito no sólo ya no tiene a la unidad por principio sino que tampoco la tiene por promesa última o postrera. Infinito diminutivo, el numeroso mar se descubre ahora expresión finita del infinito. “¡No salir jamás de los Números y los Entes!", como concluye "El abismo", quiere decir que en el mar, esto es, en la existencia como en la música, uno está constante pero finitamente expuesto al infinito inaccesible, que es tan imposible hundirse en el infinito como sustraerse al vértigo de su ilimitado límite. Sin embargo, la falta de unidad no significa la mera dispersión de lo múltiple. Si la suma es repetición y la sucesión es escansión, entonces en el mar, como en la música y en el verso, es asunto de ritmo y no de cálculo. La unicidad del ritmo, que es la forma del movimiento mismo, la discreta andadura del movimiento, sustituye a la unidad, continua y monótona, de la melodía.

Si la melodía es una corriente o una cuerda, el ritmo es un remolino o un nudo. Por eso también el tiempo es ahora otro. El tiempo de la música, de esa música que es, como una ola en el mar, un presente distendido entre pasado y futuro y del que habla el poema "La música", se descubre ahora como el 
intervalo sin presencia en el que el pasado se espera en el futuro y el futuro se recuerda en el pasado, es decir como el futuro anterior, el 'habrá sido' que según Jankelevitch es el tiempo de la música. Si el presente significaba el espacio y el movimiento en el espacio, el intervalo significa ahora el tiempo y la inmovilidad en el tiempo. Ya no se trata del mar encrespado y las agitadas pasiones sino de la calma chicha en el lacio mar de la melancolía. La melancolía no es la mera negación de las pasiones, es su afirmación apática, es decir, a la vez extrema e impasible. Todas las pasiones representadas en el mar son todavía pasiones terrestres, es decir, pasiones de la vida y del yo. Acordémonos del final de aquel poema de El Spleen de París titulado "¡Ya!", en el que desde tierra llegan, para inconcebible tristeza del narrador, las músicas de la vida en amoroso murmullo. En Baudelaire las sirenas cantan desde tierra. Prometen el olvido, sea en la forma del sueño, sea en la del aturdimiento. El vaivén del mar, ya acune, ya arrebate, nada más repite aquella distracción. "Las ondulaciones del ensueño", dice Baudelaire en la dedicatoria de El Spleen de París. Pero hay otro movimiento, menos notorio y más fundamental, pues se diría que se disimula en todos. Es lo que se llama la 'vibración': "siento vibrar en mí las pasiones todas...". Esa vibración, ese estremecimiento, esa crispación es lo contrario del olvido, pues parece estar referida a una sensibilidad anterior a la percepción, a una consciencia anterior a la reflexión. "Los sobresaltos de la consciencia", dice Baudelaire. El sobresalto tiene lugar como síncopa, es decir, en la cesura o lo que se llamó el intervalo. La cesura es lo que impide al sujeto tanto acceder a sí como perderse pura y simplemente. Por eso en el 
poema está señalada por la figura del espejo. Si la música, el mar que es la música, se descubre de pronto, en un momento muy preciso, como un espejo es para indicar que hay una distancia insalvable entre ella y el oyente, de manera que uno no puede perderse en ella, pero también que esa distancia define la intimidad misma del sujeto, es decir, que la música tiene lugar en la distancia entre el sujeto y él mismo, y de ese modo lo relaciona consigo en el instante mismo en que se pierde y en su misma pérdida. Es lo que dice Baudelaire: la música habla de ti, relata el poema o la leyenda de tu vida, es parte de ti y tú te pierdes en ella, es decir, te reencuentras a ti mismo en la prueba de tu pérdida. Reconocimiento y desposesión son los signos del espejo. De allí quizá la definición de André Hirt: la música es la ausencia a sí como relación consigo. En el gran espejo del mar es la consciencia desvelada en la que se refleja el imposible naufragio del sujeto. El poema llama a esta experiencia la 'desesperación', ya que es la desesperación de la nada, la desesperación ante la imposibilidad del no-ser. Es lo que los lectores de Las flores del mal conocen con el nombre de Spleen o de Ennui, y que nosotros traducimos 'melancolía'. ¿Qué es el ennur? Jankelevitch dice: el hundimiento en el intervalo. El intervalo viene figurado por lo que se llama la calme plat, la 'calma chicha' del mar devenido espejo. Al mar opulento de pasiones, de riquezas, de promesas, de relatos, le sucede el mar lacio, indiferente, sin ruta ni meta, sin estancia, y que es el puro intervalo del otro, ese intervalo en el que el barco sólo se hunde en la imposibilidad de hundirse y se refleja como lo que solamente se hunde -en la horizontalidad de una pura 
superficie. Si el mar deviene espejo, no podrá ya el velero convertirse en ola, fundirse con el oleaje del mar. La situación es la que describe impecablemente "El Confiteor del artista", que hay que citar entero:

¡Qué penetrante es el final de los días de otoño! ¡Ah, penetrante hasta el dolor! Pues hay ciertas sensaciones deliciosas cuya vaguedad no excluye la intensidad; y no hay punta más acerada que la del Infinito.

¡Gran delicia la de ahogar la mirada en la inmensidad del cielo y del mar! ¡Soledad, silencio, incomparable castidad del azur!, una pequeña vela que se estremece en el horizonte y que por su pequeñez y su aislamiento imita mi irremediable existencia, la melodía monótona del oleaje; todas esas cosas piensan por mí, o yo por ellas (ipues en la grandeza del ensueño el yo se pierde rápido!); esas cosas piensan, digo, pero musical y pintorescamente, sin argucias, sin silogismos, sin deducciones.

No obstante, esas ideas, ya salgan de mí o broten de las cosas, enseguida se tornan demasiado intensas. La energía en la voluptuosidad crea un malestar y un sufrimiento positivos. Mis nervios, demasiado tensos, no producen más que vibraciones estridentes y dolorosas.

Y ahora, la profundidad del cielo me consterna, su limpidez me exaspera. La insensibilidad del mar, la inmutabilidad del espectáculo me sublevan... ¡Ah! ¿Habrá que sufrir eternamente, o eternamente huir de lo bello?

Naturaleza, hechicera despiadada, rival siempre victoriosa, ¡déjame! ¡Ya no tientes mis deseos y mi orgullo! 
El estudio de la belleza es un duelo en el que el artista grita de espanto antes de ser vencido.

No pretenderemos analizar ese poema. Situémoslo solamente en nuestra lectura de "La música". En Mi corazón al desnudo escribe Baudelaire: "De la disipación y la concentración del yo. Todo está ahî". El yo se disipa en lo sensible, en el 'ensueño', dice el Confiteor, como un puro haz de sensaciones. La música tiene también en ello su papel. Por la música, dice Baudelaire, se experimenta "el culto de la sensación multiplicada". El yo se diluye en el puro medio de la sensación, lo que el poema "La música" llama el mar. Pero el Confiteor enseña otra cosa. En el horizonte, por encima de la melodía del oleaje, pequeña y solitaria, tiembla una vela, imagen, dice Baudelaire, de la irremediable existencia del yo. Es nada más que una imagen, seguramente, pero que es signo de otro movimiento. En efecto, a la subjetivación del mar, es decir, a la disipación del yo, le corresponde una concentración y una desubjetivación del yo. El infinito ya no es una inmensidad en la que el yo se anula sino una punta afilada que hiere, tensa, hace vibrar la sensibilidad, lo que Baudelaire llama los 'nervios'. Por un lado, la palabra nerfs señala el abandono del orden de la naturaleza por el de la ciudad, es decir, el océano y el éter por las olas de los techos ("Las ventanas") y los mástiles de las chimeneas ("Paisaje"), y en consecuencia el paso del desmayo al vértigo, de la languidez a la crispación; pero por otro lado la vibración, la crispación de los nervios señala que se trata de una sensibilidad no sólo extrema sino singularizada por esa extremosidad. La sensibilidad moderna, ésa que llamamos 
urbana o metropolitana y que Baudelaire inaugura poéticamente en más de un respecto y que retrospectivamente Eliot reconocerá en los metafísicos ingleses, no sólo no se expresa ya como sensualidad ni se prolonga o se interioriza como sentimiento sino que ni siquiera parece definirse por la sensación. Más bien se trata de la sensualidad de lo que escapa a lo sensible. El Confiteor llama a eso el 'pensamiento', pero un pensamiento que no se dirige al entendimiento sino que altera, tensa, crispa la sensibilidad, un pensamiento que hay que sentir con los nervios, como si hubiera que llevar los nervios hasta el pensamiento. Que lo que en esa experiencia está en juego es la música Baudelaire lo dice expresamente: "esas cosas piensan, digo, pero musical y pintorescamente, sin argucias, sin silogismos, sin deducciones". No desplegaremos los problemas implicados en esas palabras: la música como sintaxis sin semántica, más aún, sin gramática, o como síntesis sin juicio o como puro ritmo del sentido... Digamos tan sólo esto: la música afecta a la sensibilidad al modo de un pensamiento o como un dolor que despierta el pensamiento a la sensibilidad. El cuerpo se estremece igual que un barco que sufre, sus nervios producen vibraciones dolorosas y estridentes. ¿Llegaremos a decir que aquí la experiencia del shock se convierte en música? Habrá que esperar hasta Schoenberg para eso, al menos según la hipótesis de Adorno. Mejor atendamos al hecho de que aquello que en la música hiere la sensibilidad, tanto en el poema "La música" como en "El Confiteor del artista", es el infinito, del que el mar y el cielo no son más que imágenes. Ahora bien, como ha observado Lacoue-Labarthe, la sensibilidad del infinito, o simplemente del espacio, es 
sensibilidad de la pura forma de la intuición sensible. En esa experiencia, que es la experiencia de la música, la sensibilidad es conducida a su límite, a sentir la condición de toda presentación, como si la tarea de la música fuera presentar la pura posibilidad de la presentación. De allí la vocación sublime de la música. En la escucha, la sensibilidad está tensada hasta el pensamiento, hasta el dolor del pensamiento. ¿Qué es el pensamiento? Quizá pueda decirse: una cierta crispación de la sensibilidad. De ningún modo se trata entonces de responder al estímulo de una música entendida como representación de emociones sino de sostener lo inteligible en la sensibilidad, de pensar la música. Es lo que según Barthes exige la obra tardía de Beethoven: la experiencia de una inteligibilidad sensible, de lo inteligible como sensible. Recordemos tan sólo, para terminar, que el poema "La música" tenía originariamente otro título. Se llamaba: "Beethoven".

\section{Referencias Bibliográficas}

Baudelaire, C. (1951). Oeuvres Complètes. París: La Pléiade.

Barthes, R. (2002). Lo obvio y lo obtuso. Barcelona: Paidós.

Hersch, J. (2013). Tiempo y música. Barcelona: Acantilado.

Jankélévitch, V. (2005). La música y lo inefable. Barcelona: Alpha Decay

Nancy, J.-L. (2004). A la escucha. Buenos Aires: Amorrortu.

Poulet, G. (1961). Les métamorphoses du cercle. París: Plon. 